\title{
Comparative Evaluation of Antioxidant Potential of Parasitic Plant Collected from Different Hosts
}

\section{Fozia Anjum ${ }^{1 *}$, Shazia Anwer Bukhari ${ }^{1 *}$, Muhammad Shahid ${ }^{2}$, Shakeel Anwar ${ }^{3}$, Muhammad Afzal $^{4}$ and Naheed Akhter ${ }^{1}$}

${ }^{1}$ Department of Chemistry, Government College University, Faisalabad 3800, Pakistan

${ }^{2}$ Department of Chemistry and Biochemistry, University of Agriculture, Faisalabad 38040, Pakistan

${ }^{3}$ Department Plant Pathology, University of Agriculture, Faisalabad 38040, Pakistan

${ }^{4}$ Horticultural Research Institute, Ayub Agricultural Research Institute, Faisalabad, Pakistan

\begin{abstract}
Extracts of Cuscuta stem collected over different hosts were prepared by stimulated effect of ultrasonic waves using different solvents like $100 \%$ methanol, $80 \%$ methanol, $100 \%$ ethanol, $80 \%$ ethanol, water and $n$-hexane. Maximum extract yield (g/100 g of DW) was detected by using $80 \%$ methanol solvent (11.72-26.14) followed by water (10.52-22.95), 80\% ethanol (10.19-22.63), methanol (8.91-22.61), ethanol (5.92-15.12), and n-hexane (3.82-8.72). Maximum level of TPC (71.11), TFC (85.11), reducing power (2.56), DPPH scavenging activity (59.57), percent inhibition of linoleic acid peroxidation (87.49) and $\delta$-tocopherol $(100 \mu \mathrm{g}$ of $\delta-\mathrm{Toc} / \mathrm{g}$ of $\mathrm{FW}$ ) was found significantly higher $(P<0.05)$ in stem collected from Z. jojoba whereas $\alpha-(21 \mu \mathrm{g}$ of $\delta-T o c / g$ of FW) and $\Upsilon$-tocopherol $(96 \mu \mathrm{g}$ of $\delta-$ Toc/g of FW) contents were found higher $(P<0.05)$ in $E$. jambulana and $C$. latifolia. A strong correlation between total phenolics $\left(R_{2}=0.916\right)$ or reducing power $\left(R_{2}=0.561\right)$ and antioxidant activity was found in methanolic extract whereas flavonoids exhibited weak correlation with antioxidant activity.
\end{abstract}

Keywords: Cuscuta sp.; Antioxidant activity; Tocopherol; Methanol; Ethanol; n-Hexane

\section{Introduction}

Prooxidants and antioxidants are directly related to the maintenance of the health. Well known prooxidants are Reactive Oxygen Species (ROS) like superoxide anion, hydroxyl radical, hydrogen peroxide and singlet oxygen. When imbalances occur between prooxidants and antioxidants, results in cellular oxidative stress and lipoproteins degeneration that enhance the development of many diseases like cancer, aging, inflammation, cardiovascular diseases, neurodegenerative diseases, and liver injury etc [1,2].

Therefore, body cells can be protected from the attack of oxidative stress by using the diet containing antioxidants such as phenolics, flavonoids, tocopherols and vitamins called functional food, effectively protect the body cells from the attack by oxidative stress. In traditional medicines, it is believed that food and medicine has the same origin but differ in their application and uses. Human health can be promoted by using functional foods or medicated diets in the form of tonics which are prepared by using different medicinal/ herbal plants and to prevent and cure diseases $[3,4]$.

Cuscuta sp. (Convolvulaceae) is one of the commonly used herbal constituents in functional foods and medicinal tonics to nourish the different body parts. It is often added as nutrient in porridge and alcoholic beverages to improve quality of food. It is also used to prevent abortion as well as aging in clinical treatment. Previous studies have indicated that Cuscuta sp. possesses anticancer and immune stimulatory activities. In addition, Cuscuta glycoside has been demonstrated to exert anti-aging effects and enhance memory [4-7].

The purpose of the present research work was to evaluate the antioxidant potential and comparative evaluation of Cuscuta sp. Collected from number of host plants.

\section{Materials and Methods}

\section{Collection and authentication of parasitic plant material}

Fresh stems of Cuscuta sp. were collected from different plant hosts like Azdirecta indica, Zizyphus jojoba, Morus alba, Accacia Arabica, Acacia nilotica, C. latifolia, Eugenia jambulana, Melia azadirach and E. camaldulensis present in different localities of Punjab, Pakistan. These stems identified by comparing with standard herbarium specimens available in the Dept. of Botany, University of Agriculture, Faisalabad. Samples were washed under the running tap water, air dried under the shade and then homogenized to fine powder and stored in air tight bottle before further antioxidant analysis.

\section{Reagents and standards}

All chemicals of analytical grade used in this study were purchased from either E. Merck (Darmstadt. Germany) or Sigma-Aldrich (Buchs, Switzerland) unless otherwise noted. Pure standards of tocopherols [DL-a-tocopherol, (+)- $\delta$-tocopherol, and $(+)-\gamma$-tocopherol], 1,1-Diphenyl-2-picrylhydrazyl radical (DPPH, Sigma, 90.0\%), linoleic acid, food grade synthetic antioxidant butylated hydroxytoluene (BHT, $99.0 \%)$, Folin-Ciocalteu reagent $(2 \mathrm{~N})$, and gallic acid were purchased from Sigma Chemicals Co (St, Louis, MO, USA). All other chemicals of analytical grade were purchased from Merck (Darmstadt, Germany).

\section{Preparation of Cuscuta sp. extracts}

Sample (100 g) of Cuscuta powder was extracted with 1.0Litre of each of the solvent- $100 \%$ methanol, $80 \%$ methanol, $100 \%$ ethanol, $80 \%$

*Corresponding authors: Fozia Anjum, Department of Chemistry, Governmen College University, Faisalabad 3800, Pakistan, Tel: +923346575057; E-mail: foziaanjum2008@yahoo.com

Shazia Anwer Bukhari, Department of Chemistry, Government College University, Faisalabad 3800, Pakistan, Tel: +9203006637159; Fax: + 92-419200764; E-mail: Bukhari.shazia@yahoo.com

Received March 18, 2013; Accepted April 10, 2013; Published April 20, 2013

Citation: Anjum F, Bukhari SA, Shahid M, Anwar S, Afzal M, et al. (2013) Comparative Evaluation of Antioxidant Potential of Parasitic Plant Collected from Different Hosts. J Food Process Technol 4: 228. doi:10.4172/2157-7110.1000228

Copyright: $\odot 2013$ Anjum F, et al. This is an open-access article distributed under the terms of the Creative Commons Attribution License, which permits unrestricted use, distribution, and reproduction in any medium, provided the original author and source are credited. 
ethanol, water and n-hexane for two hours at room temperature in ultrasonic bath then filtered with filter paper (whattman filter paper). The residues were re-extracted twice. Extract was concentrated and lyophilized. The dried crude concentrated extracts were weighed to calculate the yield and stored at $4^{\circ} \mathrm{C}$ till for further analysis (Table 1).

\section{Antioxidant potential of Cuscuta sp.}

Total phenolic contents (TPC): Total phenolic contents of Cuscuta stem extracts were determined according to the Folin-Ciocalteu method as reported by Riaz et al. [8].

Total flavonoid contents (TFC): Total flavonoid contents was determined by modified method as described by Anjum et al. [9]

DPPH radical scavenging activity: DPPH radical scavenging activity was analyzed by following the modified method of Arshad et al. [10].

Determination of reducing power: The reducing power of the Cuscuta stem extracts was determined according to the modified method of Mahmood et al. [11].

Determination of Percent inhibition of linoleic acid peroxidation: Oxidation of lioleic acid was estimated by following the method of Khan et al. [12].

\section{Statistical analysis}

Samples of each Cuscuta extract were assayed in triplicate and data are reported as mean $(n=3 \times 3 \times 1) \pm S D(n=3 \times 3 \times 1)$. 2 - Way analysis of variance (ANOVA) at probability value of $\mathrm{p}=0.05$ was used to analyze the data using Minitab 2000 Version 13.2 statistical software (Minitab Inc. Pennsylvania, USA) [13].

\section{Results and Discussion}

Antioxidant extracts (g/100 g of dried Cuscuta stem) using different solvents were obtained from Cuscuta stems collected from different host plants and values are depicted in table 2. Maximum extract yield was detected by using $80 \%$ methanol solvent (11.72-26.14) followed by water (10.52-22.95), 80\% ethanol (10.19-22.63), methanol (8.91-22.61), ethanol (5.92-15.12), and n-hexane (3.82-8.72). This trend of extract yield indicating the fact that most of the antioxidants are soluble in more polar solvent like aqueous methanol. Similar trend of antioxidant extraction was reported by Khan et al. [12] as well as Anjum et al. [9]. In present research work, the variation in extract yields might be ascribed to the different availability of extractable components in Cuscuta stem, resulting from the varied chemical composition of host plants [14]. The amount of the antioxidant components that can be extracted from stem is mainly affected by the vigor of the ultrasonically assisted extraction procedure, which may probably vary from sample to sample. Amongst other contributing factors, efficiency of the extracting solvent to dissolve endogenous compounds might also be very important $[15,16]$.

\section{Antioxidant potential of Cuscuta sp.}

Total phenolic contents (TPC): Phenolics are well established to show antioxidant activity and contribute to human health. Total phenolic contents of stems extracts using different solvents are presented in table 2. Among the different solvent systems, aqueous methanolic extract of stem collected from $Z$. jojoba offered the highest

\begin{tabular}{|c|c|c|c|c|c|c|}
\hline \multirow{2}{*}{ Cuscuta stem collected from } & \multicolumn{6}{|c|}{ Solvent used for extraction } \\
\hline & Methanol & $80 \%$ methanol & Ethanol & $80 \%$ ethanol & water & n-hexane \\
\hline A.indica & $22.61_{\mathrm{a}}^{\mathrm{b}} \pm 0.78$ & $26.14_{a}^{a} \pm 0.81$ & $17.29^{d} \pm 0.33$ & $21.18_{a}^{c} \pm 0.55$ & $22.95_{a}^{b} \pm 0.14$ & $8.72_{a}{ }^{e} \pm 0.12$ \\
\hline Z.jojoba & $19.24_{b}{ }^{c} \pm 0.71$ & $26.01_{\mathrm{a}}^{\mathrm{a}} \pm 0.91$ & $14.28_{b}{ }^{d} \pm 0.92$ & $22.63_{a}^{b} \pm 0.51$ & $21.37_{\mathrm{a}}^{\mathrm{b}} \pm 0.32$ & $7.21_{b}{ }^{e} \pm 0.10$ \\
\hline M.alba & $15.21_{c}^{a} \pm 0.51$ & $13.21_{e}^{c} \pm 0.32$ & $11.64_{c}{ }^{d} \pm 0.58$ & $12.92_{d}{ }^{c} \pm 0.28$ & $14.21_{d}{ }^{b} \pm 0.33$ & $3.82_{d}{ }^{e} \pm 0.31$ \\
\hline A.arabica & $19.01_{b}{ }^{a} \pm 0.21$ & $19.92_{c}^{a} \pm 0.57$ & $11.01_{c}{ }^{d} \pm 0.55$ & $15.21_{c}{ }^{c} \pm 0.13$ & $17.21_{c}^{b} \pm 0.57$ & $5.27_{c}{ }^{e} \pm 0.52$ \\
\hline A.nilotica & $11.10_{d}{ }^{d} \pm 0.20$ & $15.02{ }_{d}^{b} \pm 0.32$ & $8.17_{d}{ }^{e} \pm 0.34$ & $13.21_{d}{ }^{c} \pm 0.12$ & $16.92_{c}^{a} \pm 0.92$ & $8.26_{a}{ }^{e} \pm 0.33$ \\
\hline C.latifolia & $8.91_{e}{ }^{c} \pm 0.12$ & $11.72_{e}^{a} \pm 0.71$ & $5.92_{e}^{d} \pm 0.61$ & $10.19_{e}^{b} \pm 0.41$ & $11.01_{e}{ }^{a} \pm 0.27$ & $5.71_{c}{ }^{d} \pm 0.31$ \\
\hline E.jambulana & $12.17_{d}^{a} \pm 0.33$ & $12.03_{e}^{a} \pm 0.94$ & $10.38_{c}{ }^{b} \pm 0.72$ & $10.93_{e}^{b} \pm 0.51$ & $10.52_{e}^{b} \pm 0.27$ & $4.27_{d}^{c} \pm 0.15$ \\
\hline M. Azadirech & $13.25_{d}^{d} \pm 0.15$ & $20.19_{c}^{a} \pm 0.11$ & $15.12_{b}{ }^{c} \pm 0.17$ & $16.29_{c}{ }^{c} \pm 0.26$ & $17.21_{c}{ }^{b} \pm 0.16$ & $5.42_{c}{ }^{e} \pm 0.19$ \\
\hline E.camaldulensis & $18.01_{b}{ }^{b} \pm 0.17$ & $23.01_{b}{ }^{a} \pm 0.36$ & $14.81_{b}{ }^{c} \pm 0.11$ & $17.69_{b}^{b} \pm 0.32$ & $19.61_{b}{ }^{b} \pm 0.11$ & $7.33_{b}{ }^{d} \pm 0.23$ \\
\hline
\end{tabular}

Values (mean \pm SD) are average of three samples of each Cuscuta stem, analyzed individually in triplicate $(n=1 \times 3 \times 3)$, $(P<0.05)$; DW $=$ dry weight; Superscript letters within the same row indicate significant $(P<0.05)$ differences of means within the extracting solvent; Subscript letters within the same column indicate significant $(P<0.05)$ differences of means among the Cuscuta stem collected from different host plant.

Table 1: Extract yield (g/100 g of DW) of Cuscuta stem collected from different host plants using different solvents.

\begin{tabular}{|c|c|c|c|c|c|c|}
\hline \multirow{2}{*}{ Cuscuta stem collected from } & \multicolumn{6}{|c|}{ Solvent used for extraction } \\
\hline & Methanol & $80 \%$ methanol & Ethanol & $80 \%$ ethanol & water & n-hexane \\
\hline A.indica & $62.19_{b}^{b} \pm 0.31$ & $66.30_{b}^{a} \pm 2.1$ & $45.12_{c}{ }^{d} \pm 0.89$ & $54.32_{b}{ }^{c} \pm 2.01$ & $40.13_{c}^{d} \pm 1.65$ & $8.21_{d}{ }^{e} \pm 0.49$ \\
\hline Z.jojoba & $66.20_{a}^{b} \pm 0.64$ & $71.11_{a}^{a} \pm 3.52$ & $51.02_{a}^{c} \pm 1.79$ & $54.12_{b}{ }^{c} \pm 1.21$ & $32.11_{\mathrm{e}}^{\mathrm{d}} \pm 0.99$ & $15.29_{b}{ }^{d} \pm 0.51$ \\
\hline M.alba & $47.21_{d}{ }^{c} \pm 0.92$ & $61.01_{c}^{a} \pm 2.18$ & $44.03_{c}^{d} \pm 1.37$ & $52.91_{c}^{b} \pm 1.63$ & $43.51_{b}{ }^{d} \pm 0.93$ & $19.92_{\mathrm{a}}{ }^{\mathrm{e}} \pm 1.01$ \\
\hline A.arabica & $39.42_{e}{ }^{c} \pm 0.66$ & $51.29_{d}{ }^{a} \pm 2.01$ & $33.17_{e}^{d} \pm 0.98$ & $45.11_{d}^{b} \pm 2.01$ & $39.71_{c}{ }^{c} \pm 0.38$ & $8.12_{d}{ }^{e} \pm 0.52$ \\
\hline A.nilotica & $41.29_{\mathrm{e}}^{\mathrm{b}} \pm 0.59$ & $47.02_{\mathrm{e}}^{\mathrm{a}} \pm 2.13$ & $35.38_{d}^{d} \pm 0.75$ & $40.02_{e}^{b} \pm 1.49$ & $37.28_{d}{ }^{c} \pm 0.79$ & $11.25_{c}{ }^{e} \pm 0.77$ \\
\hline C.latifolia & $52.01_{c}^{a} \pm 0.27$ & $52.98_{d}{ }^{a} \pm 2.32$ & $49.81_{b}{ }^{c} \pm 0.61$ & $51.21_{c}^{b} \pm 1.30$ & $40.82_{c}^{d} \pm 0.62$ & $10.21_{c}^{e} \pm 1.01$ \\
\hline E.jambulana & $61.39_{b}^{b} \pm 1.28$ & $69.1_{a}^{a} \pm 1.99$ & $52.29_{a}^{c} \pm 1.42$ & $58.15_{a}^{b} \pm 1.02$ & $39.16_{c}^{d} \pm 1.03$ & $7.25_{d}{ }^{e} \pm 0.28$ \\
\hline M. Azadirech & $59.34_{b}{ }^{a} \pm 1.9$ & $62.40_{c}{ }^{a} \pm 3.02$ & $51.28_{a}^{c} \pm 0.99$ & $55.29_{b}^{b} \pm 1.11$ & $41.26_{c}^{d} \pm 0.59$ & $11.0_{c}^{e} \pm 0.32$ \\
\hline E.camaldulensis & $55.32_{c}^{b} \pm 0.99$ & $59.01_{c}{ }^{a} \pm 2.49$ & $49.35_{b}^{c} \pm 1.01$ & $49.10_{c}^{c} \pm 1.72$ & $50.11_{a}{ }^{c} \pm 0.37$ & $5.92 e^{d} \pm 0.27$ \\
\hline
\end{tabular}

Values (mean \pm SD) are average of three samples of each Cuscuta stem, analyzed individually in triplicate $(n=1 \times 3 \times 3)$, $(P<0.05)$; Superscript letters within the same row indicate significant $(P<0.05)$ differences of means within the extracting solvent; Subscript letters within the same column indicate significant $(P<0.05)$ differences of means among the Cuscuta stem collected from different host plant.

Table 2: Total phenolic contents $(\mathrm{mg} / \mathrm{g})$ of Cuscuta stem collected from different host plants using different solvents. 
TPC 71.11(mg/g), followed by E. jambulana (69.11), A. indica (66.30), M. Azadirech (62.40), M. alba (61.01), E. camaldulensis (59.01), C. latifolia (52.98), A. arabica (51.29) and A. nilotica (47.02). Other solvent extracts except $\mathrm{n}$-hexane also exhibited considerable amount of TPC. Absolute methanol, absolute ethanol, $80 \%$ ethanol, water and n-hexane extracted TPC in the range of 39.42-66.20, 33.17-52.49, 40.02-58.15, 32.11-50.11 and 5.92-19.92 respectively. It is clear from the present research findings that among all the solvent extracts; the aqueous methanol/ethanol and absolute methanol extracts showed the highest TPC. This may be due to the fact that phenolics are often extracted in higher amounts in more polar solvents. Ghimiri et al. [17] also detected total phenolic contents of $123.33 \mathrm{mg} \mathrm{GAE} / \mathrm{g}$ of methanolic extract in Cuscuta stems.

Total flavonoid contents (TFC): TFC of various Cuscuta stems extracted with six solvent systems using ultrasonically stimulated extraction technique are given in table 3. Among the Cuscuta stems, aqueous methanolic extract of stem collected from $Z$. jojoba tree offered highest level of TFC mg of CE/g of DW (85.11) followed by $A$. indica (82.91), A. Arabica (73.28), A. nilotica (73.29), M. alba (72.03), M. azadirach (70.81), E. camaldulensis (67.11), C. latifolia (61.29) and E. jambulana (53.11). Other solvent systems also extracted significant amount of flavonoids. Absolute methanol/ethanol, $80 \%$ ethanol, water and n-hexane also partitioned TFC in the range of 47.05-81.01, 43.20$65.17,46.36-77.28,51.13-80.01$ and 3.41-16.24 respectively. Papuc et al. [18] reported the flavonoids $2035.16 \mu \mathrm{g}$ CAT/mL in Cuscuta sp whereas Ghimire et al. [17] detected $37.87 \mathrm{mg} \mathrm{QE} / \mathrm{g}$ of methanolic extract of Cuscuta sp. Gupta and Sharma [19], Sepehr et al. [20] and Udavant et al. [21] also give the indications of flavonoids in Cuscuta sp.
Flavonoid are known to be promising antioxidant acting as free radical scavengers with activities influenced by their hydroxylation pattern. So flavonoids may prevent a number of diseases created by free radicals.

Reducing power: The results showing the effects of extracting solvent on the reducing potential of extracts of different Cuscuta stems at concentration of $10 \mathrm{mg} / \mathrm{mL}$ are shown in table 4 . The absorbance values of the all stems extract solutions (Concentration of $10 \mathrm{mg} /$ $\mathrm{mL}$ ) detected in this assay ranged from 0.08 to 2.56 in aq. ME except $A$. indica and E. jambulana who gave maximum reducing potential values in ME. The reducing potential in aq. ME follow the order of effectiveness as: aq. ME of $Z$. jojoba (2.56) $>\mathrm{ME}$ of $A$. indica (2.15) $>\mathrm{ME}$ E. jambulana (2.11)>aq. ME of C. latifolia (1.91)>aq. ME of $M$. alba (1.63)>aq. ME of E. camaldulensis (1.47)>aq. ME of $M$. azadirach (1.35)>aq. ME of A. Arabica (1.31)>aq. ME of A. nilotica (1.08). In general, good reducing power in the present analysis is complimentary to the TPC. The plant extracts with higher levels of total phenolics also exhibit greater reducing power.

DPPH scavenging activity: Scavenging activity of Cuscuta stems extract is depicted in table 5 . Absorbance in this assay was recorded at 0.5 to $10 \mathrm{~min}$ time intervals from initiation of the reaction. At the beginning of the reaction, scavenging activity was similar but changed with increase in the reaction time until it stabilized by the 10th min. Significant $(\mathrm{p}<0.05)$ differences of DPPH scavenging capacities among extracts were observed at $5^{\text {th }}$ minute of the reaction. The DPPH scavenging ability of the sample extracts was reported as the percent of DPPH scavenged (\% DPPH. scavenging). As expected, a higher percent of DPPH scavenging is correlated to a higher antioxidant activity due to polyphenolic, carotenoids, flavonoids and phenolic compounds

\begin{tabular}{|c|c|c|c|c|c|c|}
\hline \multirow{2}{*}{ Cuscuta stem collected from } & \multicolumn{6}{|c|}{ Solvent used for extraction } \\
\hline & Methanol & $80 \%$ methanol & Ethanol & $80 \%$ ethanol & water & n-hexane \\
\hline A.indica & $77.19_{b}^{b} \pm 1.23$ & $82.91_{a}^{a} \pm 0.71$ & $61.28_{d}^{b} \pm 1.21$ & $75.11_{c}^{a} \pm 2.01$ & $77.13_{\mathrm{b}}{ }^{\mathrm{a}} \pm 1.01$ & $10.11_{\mathrm{e}}^{\mathrm{b}} \pm 0.42$ \\
\hline Z.jojoba & $81.01_{b}{ }^{a} \pm 0.99$ & $85.11_{a}^{a} \pm 0.93$ & $65.17_{d}^{a} \pm 1.01$ & $77.28_{c}^{a} \pm 1.11$ & $80.01_{b}{ }^{a} \pm 1.01$ & $05.02 \pm 0.71$ \\
\hline M.alba & $68.11_{b}{ }^{c} \pm 0.72$ & $72.03_{a}^{b} \pm 0.69$ & $52.92_{d}{ }^{c} \pm 0.93$ & $60.03_{c}^{c} \pm 0.93$ & $68.32_{b}{ }^{b} \pm 0.93$ & $16.24_{\mathrm{e}}{ }^{\mathrm{a}} \pm 0.82$ \\
\hline A.arabica & $69.01_{b}{ }^{c} \pm 0.91$ & $73.28_{a}^{b} \pm 1.29$ & $49.32_{d}^{d} \pm 0.78$ & $54.02_{c}^{d} \pm 0.97$ & $59.31_{c}^{c} \pm 0.67$ & $03.41_{e}{ }^{d} \pm 0.52$ \\
\hline A.nilotica & $70.01_{a}^{c} \pm 1.13$ & $73.29_{a}^{b} \pm 1.42$ & $53.11_{d}{ }^{c} \pm 0.82$ & $62.18_{b}^{b} \pm 0.59$ & $59.45_{c}^{c} \pm 1.20$ & $06.29_{\mathrm{e}}{ }^{\mathrm{c}} \pm 0.61$ \\
\hline C.latifolia & $47.05_{d}{ }^{e} \pm 1.02$ & $61.29_{a}^{d} \pm 0.88$ & $52.05_{c}^{c} \pm 1.03$ & $56.77_{b}^{d} \pm 1.03$ & $54.12_{b}{ }^{d} \pm 0.59$ & $10.32_{\mathrm{e}}^{\mathrm{b}} \pm 0.44$ \\
\hline E.jambulana & $47.09_{b}{ }^{e} \pm 0.69$ & $53.11_{\mathrm{a}}^{\mathrm{e}} \pm 1.02$ & $43.20_{c}^{e} \pm 0.68$ & $46.36_{b}{ }^{e} \pm 1.71$ & $51.13_{\mathrm{a}}^{\mathrm{e}} \pm 1.21$ & $07.39_{d}{ }^{c} \pm 0.20$ \\
\hline M. Azadirech & $61.29_{b}^{d} \pm 0.81$ & $70.81^{b}{ }_{a} \pm 0.73$ & $60.18_{b}^{b} \pm 0.83$ & $63.82_{b}^{b} \pm 1.11$ & $59.04_{c}{ }^{c} \pm 0.73$ & $05.93_{d}{ }^{c} \pm 0.11$ \\
\hline E.camaldulensis & $65.02{ }_{a}^{d} \pm 1.82$ & $67.11_{\mathrm{a}}^{\mathrm{c}} \pm 1.41$ & $53.20_{d}^{c} \pm 1.11$ & $59.12_{b}{ }^{c} \pm 0.68$ & $55.31_{c}^{d} \pm 0.82$ & $08.19^{c} \pm 0.27$ \\
\hline
\end{tabular}

Values (mean $\pm \mathrm{SD}$ ) are average of three samples of each Cuscuta stem, analyzed individually in triplicate $(n=1 \times 3 \times 3)$, $(P<0.05)$; Superscript letters within the same row indicate significant $(P<0.05)$ differences of means within the extracting solvent; Subscript letters within the same column indicate significant $(P<0.05)$ differences of means among the Cuscuta stem collected from different host plant.

Table 3: Total flavonoids contents ( $\mathrm{mg}$ of $\mathrm{CE} / \mathrm{g}$ of DW) of Cuscuta stem collected from different host plants using different solvents.

\begin{tabular}{|c|c|c|c|c|c|c|}
\hline \multirow{2}{*}{ Cuscuta stem collected from } & \multicolumn{6}{|c|}{ Solvent used for extraction } \\
\hline & Methanol & $80 \%$ methanol & Ethanol & $80 \%$ ethanol & water & n-hexane \\
\hline A.indica & $2.15_{a}^{a} \pm 0.08$ & $1.81_{b}^{b} \pm 0.03$ & $0.99_{c}{ }^{c} \pm 0.01$ & $2.01_{\mathrm{a}}^{\mathrm{a}} \pm 0.01$ & $1.87_{b}^{a} \pm 0.01$ & $0.09_{d}{ }^{c} \pm 0.00$ \\
\hline Z.jojoba & $1.21_{b}{ }^{c} \pm 0.03$ & $2.56_{a}^{a} \pm 0.07$ & $1.02_{c}^{b} \pm 0.02$ & $1.11_{b}^{b} \pm 0.01$ & $1.08{ }_{c}{ }^{c} \pm 0.01$ & $0.25_{d}^{b} \pm 0.00$ \\
\hline M.alba & $0.27_{\mathrm{e}}^{\mathrm{e}} \pm 0.11$ & $1.63_{a}^{c} \pm 0.05$ & $0.63_{b}{ }^{e} \pm 0.01$ & $0.55_{c}^{d} \pm 0.05$ & $0.52{ }_{c}^{d} \pm 0.04$ & $0.44_{d}{ }^{a} \pm 0.001$ \\
\hline A.arabica & $0.58_{d}{ }^{e} \pm 0.16$ & $1.31_{a}{ }^{d} \pm 0.07$ & $1.00_{b}^{b} \pm 0.01$ & $0.92_{c}{ }^{c} \pm 0.02$ & $1.09_{b}{ }^{c} \pm 0.01$ & $0.08_{e}{ }^{c} \pm 0.002$ \\
\hline A.nilotica & $1.01_{a}^{d} \pm 0.09$ & $1.08_{a} \pm 0.05$ & $0.92_{b}{ }^{c} \pm 0.04$ & $0.68_{c}^{d} \pm 0.03$ & $1.02{ }_{a}{ }^{c} \pm 0.03$ & $0.42_{d}{ }^{a} \pm 0.001$ \\
\hline C.latifolia & $1.63_{b}^{b} \pm 0.05$ & $1.91_{a}^{b} \pm 0.03$ & $1.22_{c}^{a} \pm 0.02$ & $0.71_{d}^{d} \pm 0.01$ & $0.99_{d}{ }^{c} \pm 0.02$ & $0.22_{\mathrm{e}}^{\mathrm{b}} \pm 0.001$ \\
\hline E.jambulana & $2.11_{\mathrm{a}}^{\mathrm{a}} \pm 0.13$ & $1.86_{b}^{b} \pm 0.09$ & $1.09_{c}^{b} \pm 0.03$ & $0.62_{d}^{d} \pm 0.01$ & $1.01_{c}^{c} \pm 0.01$ & $0.19_{\mathrm{e}}^{\mathrm{b}} \pm 0.002$ \\
\hline M. Azadirech & $1.01_{b}{ }^{d} \pm 0.11$ & $1.35_{a}^{d} \pm 0.05$ & $0.72_{c}^{d} \pm 0.02$ & $0.21_{\mathrm{e}}^{\mathrm{e}} \pm 0.02$ & $0.84_{c}{ }^{d} \pm 0.02$ & $0.41_{d}{ }^{a} \pm 0.003$ \\
\hline E.camaldulensis & $1.05_{c}^{d} \pm 0.07$ & $1.47_{a}^{d} \pm 0.11$ & $1.02_{c}^{b} \pm 0.04$ & $0.59_{d} \pm 0.01$ & $1.11_{b}^{b} \pm 0.02$ & $0.08_{e}{ }^{c} \pm 0.001$ \\
\hline
\end{tabular}

Values (mean \pm SD) are average of three samples of each Cuscuta stem, analyzed individually in triplicate $(n=1 \times 3 \times 3)$, $(P<0.05)$; Superscript letters within the same row indicate significant $(P<0.05)$ differences of means within the extracting solvent; Subscript letters within the same column indicate significant $(P<0.05)$ differences of means among the Cuscuta stem collected from different host plant.

Table 4: Reducing power (expressed as absorbance values at $700 \mathrm{~nm}$ ) of Cuscuta stem collected from different host plants using different solvents. 
[22]. All stem extracts possessed free radical scavenging properties but to varying degrees, ranging from 20.12 to $79.57 \%$ DPPH scavenging. This wide range of antioxidant activity may be attributable to the wide variety of bioactive compounds such as phenolics, flavonoids, carotenoids and tannins [17]. Generally aq. ME (44.29-79.57\%), aq. EE (39.25-64.02\%) and absolute ME (33.15-56.02) showed better DPPH scavenging activity than absolute ethanol (29.28-50.04\%), water (25.02$44.28 \%$ ) and $n$-hexane. A maximum scavenging activity was offered by aq. ME of $Z$. jojoba (79.57\%), followed by aq. ME of $A$. indica $(65.11 \%)$, aq. ME of E. jambulana (63.82\%), aq. ME of A. nilotica (57.08\%), aq. EE of M. azadirach (54.41\%), aq. ME of A. Arabica (51.03\%), aq. ME of C. latifolia (50.28\%), aq EE of E. camaldulensis (50.10\%) and aq. ME of M. alba (44.29\%) whereas Ghimiri et al. [17] detected $84.67 \%$ DPPH scavenging activity of methanolic extract of Cuscuta stem. It has well established that free radical scavenging activity of stem extracts is mainly due to phenolic compounds. Ashwani et al. [23] reported the significant free radical scavenging activity of alcoholic extract of Cuscuta reflexa as compared to water extracts.

Percent inhibition of linoleic acid peroxidation: The present data were also compared with that of the synthetic antioxidant BHT (Reference compound), which exhibited inhibition of linoleic acid oxidation at a level of $84.21 \%$. Among Cuscuta stem extracts, maximum inhibition was noted by aq. ME (45.31-87.49\%) followed by ME (44.02-83.01\%), aq. EE (49.11-82.19\%), EE (47.38-72.18\%), water (27.04-61.03\%) and n-hexane (11.19-23.55\%). Aq. ME of $Z$. jojoba offered highest level of inhibition (87.49\%), followed by aq. EE of $A$. indica (82.19\%), aq. ME of A. nilotica (79.08\%), aq. EE of C. latifolia
(65.11\%), aq. EE of E. jambulana (62.18\%), EE of A. Arabica (61.41\%), aq. EE of M. azadirach (61.22\%), aq. EE of E. camaldulensis $(56.03 \%)$ and aq. ME of M. alba (51.05\%) (Table 6).

Tocopherol contents: Tocopherols are biologically important antioxidants that are correlated with the reduction in heart diseases, delay of Alzheimer's disease, and preclusion of cancer. Especially, a-tocopherol (vitamin E) prevents oxidation of body lipids including polyunsaturated fatty acids and lipid components of cells and organelle membranes. $\delta$ - tocopherol has maximum antioxidant activity. In Cuscuta stems, $\alpha$-, $\Upsilon$ - and $\delta$-tocopherols were detected by HPLC method. $\delta$-tocopherol $(28-160 \mu \mathrm{g} / \mathrm{g})$ was found maximum in all Cuscuta stems followed by $\Upsilon$-tocopherol (10-96 $\mu \mathrm{g} / \mathrm{g})$ and $\alpha$-tocopherol $(08-21 \mu \mathrm{g} / \mathrm{g})$. A significantly $(\mathrm{P}<0.05)$ higher concentration of sigma tocopherol $\mu \mathrm{g} / \mathrm{g}$ (160) was detected in Cuscuta stems collected from A. indica followed by E. camaldulensis (101), Z. jojoba (100), A. nilotica (91), M. alba (67), E. jambulana (51), A. Arabica (45), C. latifolia (39) and $M$. azadirach (28). Maximum level of gamma tocopherol (96) was estimated in C. latifolia whereas alpha tocopherol was detected maximum in E. jambulana (21). Thomas et al. and Szimanska and Kruk [24,25] also reported highest contents of gamma and sigma tocopherol contents in different Cuscuta sp. Tocopherol is group of lipophilic antioxidant synthesized by photosynthetic organisms. Their antioxidant function is attributed to inhibition of membrane lipid peroxidation and scavenging of reactive oxygen species. Since a rich source of tocopherol, Cuscuta stems can be used in food, feed, pharmaceutical, cosmetics and resins (Table 7).

\begin{tabular}{|c|c|c|c|c|c|c|}
\hline \multirow{2}{*}{$\begin{array}{l}\text { Cuscuta stem collected } \\
\text { from }\end{array}$} & \multicolumn{6}{|c|}{ Solvent used for extraction } \\
\hline & Methanol & $80 \%$ methanol & Ethanol & $80 \%$ ethanol & Water & n-hexane \\
\hline A.indica & $52.13_{b}^{b} \pm 1.22$ & $65.11_{\mathrm{a}}^{\mathrm{b}} \pm 2.01$ & $50.04_{b}{ }^{a} \pm 2.01$ & $51.39_{b}{ }^{c} \pm 1.51$ & $31.02_{c}{ }^{d} \pm 1.42$ & $20.18_{d}{ }^{c} \pm 1.11$ \\
\hline Z.jojoba & $56.02_{c}^{a} \pm 1.71$ & $79.57_{\mathrm{a}}^{\mathrm{a}} \pm 1.11$ & $48.11_{d}{ }^{a} \pm 2.17$ & $64.02_{b}{ }^{a} \pm 1.42$ & $28.13_{e} \pm 1.91$ & $29.31_{\mathrm{e}}^{\mathrm{a}} \pm 1.01$ \\
\hline M.alba & $37.02_{b}{ }^{d} \pm 1.01$ & $44.29^{d} \pm 1.02$ & $29.28_{c}^{d} \pm 1.28$ & $39.25_{b}{ }^{e} \pm 1.87$ & $31.11_{c}{ }^{d} \pm 1.50$ & $20.12_{d}{ }^{c} \pm 1.05$ \\
\hline A.arabica & $33.15_{c}^{d} \pm 0.99$ & $51.03^{c}{ }^{c} \pm 1.02$ & $36.04_{b}{ }^{c} \pm 1.92$ & $49.02_{a}{ }^{c} \pm 1.05$ & $25.02_{\mathrm{e}}{ }^{\mathrm{e}} \pm 1.02$ & $30.18_{d}{ }^{a} \pm 1.36$ \\
\hline A.nilotica & $36.04{ }_{c}^{d} \pm 0.81$ & $47.08 \pm 1.52$ & $35.16_{c}^{c} \pm 1.11$ & $42.11_{b}{ }^{d} \pm 1.06$ & $33.12_{d}{ }^{c} \pm 1.20$ & $24.39_{\mathrm{e}}^{\mathrm{b}} \pm 1.92$ \\
\hline C.latifolia & $41.27_{b}{ }^{c} \pm 1.01$ & $50.28_{a}^{c} \pm 0.81$ & $37.08_{c}^{c} \pm 1.62$ & $48.33_{a}^{c} \pm 1.55$ & $35.01_{c}^{c} \pm 2.01$ & $21.07_{d}^{c} \pm 1.20$ \\
\hline E.jambulana & $44.15_{c}^{b} \pm 1.03$ & $63.82_{a}^{b} \pm 2.11$ & $41.20_{c}^{b} \pm 2.01$ & $54.10_{b}^{b} \pm 1.27$ & $44.28_{c}{ }^{a} \pm 1.22$ & $23.22_{d}^{b} \pm 1.28$ \\
\hline M. Azadirech & $47.01_{b}{ }^{b} \pm 0.62$ & $52.93_{\mathrm{a}}^{\mathrm{c}} \pm 1.84$ & $48.02_{b}{ }^{a} \pm 1.90$ & $54.41_{\mathrm{a}}^{\mathrm{b}} \pm 1.62$ & $38.13_{c}^{b} \pm 1.83$ & $28.07_{d}{ }^{a} \pm 1.22$ \\
\hline E.camaldulensis & $39.11_{c}^{c} \pm 1.03$ & $42.06_{b}{ }^{d} \pm 1.52$ & $43.59_{b}^{b} \pm 1.62$ & $50.10_{a}^{c} \pm 1.99$ & $29.48_{d}^{d} \pm 1.61$ & $25.06_{e}^{b} \pm 1.21$ \\
\hline
\end{tabular}

Values (mean \pm SD) are average of three samples of each Cuscuta stem, analyzed individually in triplicate $(n=1 \times 3 \times 3)$, $(P<0.05)$; Superscript letters within the same row indicate significant $(P<0.05)$ differences of means within the extracting solvent; Subscript letters within the same column indicate significant $(P<0.05)$ differences of means among the Cuscuta stem collected from different host plant.

Table 5: DPPH Scavenging activity (\%) of Cuscuta stem collected from different host plants using different solvents.

\begin{tabular}{|c|c|c|c|c|c|c|}
\hline \multirow{2}{*}{ Cuscuta stem collected from } & \multicolumn{6}{|c|}{ Solvent used for extraction } \\
\hline & Methanol & $80 \%$ methanol & Ethanol & $80 \%$ ethanol & water & n-hexane \\
\hline A.indica & $71.02_{c}^{b} \pm 1.22$ & $77.11_{b}^{b} \pm 2.04$ & $65.29_{d}^{b} \pm 1.33$ & $82.19_{a}^{a} \pm 2.03$ & $61.03_{d}{ }^{a} \pm 1.11$ & $11.19_{e} \pm 0.89$ \\
\hline Z.jojoba & $83.01_{b}{ }^{a} \pm 2.10$ & $87.49{ }_{a}^{a} \pm 1.99$ & $72.18_{c}^{a} \pm 1.81$ & $73.26_{c}^{b} \pm 1.79$ & $49.02_{d}^{b} \pm 1.53$ & $20.00_{e}^{a} \pm 0.99$ \\
\hline M.alba & $45.23_{b}^{e} \pm 1.61$ & $51.02_{\mathrm{a}}^{\mathrm{e}} \pm 1.82$ & $42.02_{b}{ }^{e} \pm 1.28$ & $49.11_{\mathrm{a}}^{\mathrm{e}} \pm 1.57$ & $32.18_{c}^{d} \pm 1.92$ & $17.21_{d}^{b} \pm 0.62$ \\
\hline A.arabica & $51.28_{c}{ }^{d} \pm 1.32$ & $56.33_{b}{ }^{d} \pm 1.30$ & $61.41_{\mathrm{a}}^{\mathrm{b}} \pm 1.32$ & $59.08_{a}^{c} \pm 2.01$ & $43.17_{d}^{c} \pm 2.03$ & $23.55_{\mathrm{e}}^{\mathrm{a}} \pm 1.01$ \\
\hline A.nilotica & $82.59_{a}^{a} \pm 1.03$ & $79.01_{b}^{b} \pm 1.65$ & $72.18_{c}^{a} \pm 1.00$ & $77.30_{b}^{b} \pm 1.62$ & $29.17_{d}^{e} \pm 1.74$ & $13.29_{\mathrm{e}}{ }^{\mathrm{c}} \pm 1.32$ \\
\hline C.latifolia & $61.02_{b}{ }^{c} \pm 1.11$ & $63.29_{b}{ }^{c} \pm 1.49$ & $56.48_{c}^{c} \pm 2.19$ & $65.11_{a}{ }^{c} \pm 2.03$ & $31.23_{d}^{d} \pm 2.84$ & $12.20_{\mathrm{e}}^{\mathrm{c}} \pm 1.00$ \\
\hline E.jambulana & $47.08_{c}{ }^{e} \pm 1.43$ & $51.11_{\mathrm{b}}{ }^{\mathrm{e}} \pm 2.42$ & $53.20_{b}{ }^{c} \pm 1.62$ & $62.18_{a}^{c} \pm 1.62$ & $33.92_{d}^{d} \pm 2.11$ & $15.04_{e}^{b} \pm 0.93$ \\
\hline M. Azadirech & $44.02_{b}{ }^{e} \pm 1.81$ & $45.31_{\mathrm{b}}{ }^{\mathrm{f}} \pm 2.71$ & $49.37_{c}^{d} \pm 1.63$ & $61.22_{a}{ }^{c} \pm 1.93$ & $27.04_{d}{ }^{e} \pm 1.60$ & $21.83_{e}^{a} \pm 0.62$ \\
\hline E.camaldulensis & $51.27_{c}^{d} \pm 1.06$ & $63.01_{\mathrm{a}}^{\mathrm{c}} \pm 1.49$ & $47.38_{d}^{d} \pm 1.99$ & $56.03_{b}{ }^{d} \pm 2.04$ & $35.06_{e}^{d} \pm 1.73$ & $13.27_{f}^{c} \pm 1.11$ \\
\hline
\end{tabular}

Values (mean $\pm \mathrm{SD}$ ) are average of three samples of each Cuscuta stem, analyzed individually in triplicate $(n=1 \times 3 \times 3)$, $(P<0.05)$; Superscript letters within the same row indicate significant $(P<0.05)$ differences of means within the extracting solvent; Subscript letters within the same column indicate significant $(P<0.05)$ differences of means among the Cuscuta stem collected from different host plant.

Table 6: Percent inhibition of linoleic acid peroxidation extracts of Cuscuta stem collected from different host plants using different solvents. 


\begin{tabular}{|c|c|c|c|}
\hline \multirow[t]{2}{*}{ Cuscuta stem collected from } & \multicolumn{3}{|c|}{ Tocopherol contents $(\mu \mathrm{g} / \mathrm{g})$} \\
\hline & $\alpha$-Tocopherol & $\delta$-Tocopherol & Y-tocopherol \\
\hline A.indica & $15.42^{c} \pm 0.31$ & $160.41^{\mathrm{a}} \pm 2.19$ & $10.02^{\mathrm{h}} \pm 0.69$ \\
\hline Z.jojoba & $10.01^{\mathrm{e}} \pm 0.03$ & $100.26^{b} \pm 3.11$ & $71.03^{b} \pm 1.81$ \\
\hline M.alba & $11.04^{\mathrm{e}} \pm 0.11$ & $67.13^{d} \pm 1.73$ & $26.02^{f} \pm 0.70$ \\
\hline A.arabica & $09.36^{e} \pm 0.001$ & $45.24^{\mathrm{e}} \pm 1.11$ & $34.14^{\mathrm{e}} \pm 0.51$ \\
\hline A.nilotica & $13.12^{\mathrm{d}} \pm 0.79$ & $91.05^{c} \pm 0.93$ & $16.42^{\mathrm{h}} \pm 0.55$ \\
\hline C.latifolia & $18.04^{b} \pm 0.93$ & $39.01^{\mathrm{e}} \pm 0.62$ & $96.01^{\mathrm{a}} \pm 1.92$ \\
\hline E.jambulana & $21.01^{\mathrm{a}} \pm 0.91$ & $51.01^{e} \pm 0.81$ & $61.27^{c} \pm 1.01$ \\
\hline M. Azadirech & $15.01^{c} \pm 0.63$ & $28.36^{f} \pm 0.21$ & $40.10^{d} \pm 0.93$ \\
\hline E.camaldulensis & $08.62^{\mathrm{e}} \pm 0.002$ & $101.25^{b} \pm 2.18$ & $73.03^{b} \pm 0.79$ \\
\hline
\end{tabular}

Values (mean \pm SD) are average of three samples of each Cuscuta stem, analyzed individually in triplicate $(n=1 \times 3 \times 3)$, $(P<0.05$; Subscript letters within the same column indicate significant $(P<0.05)$ differences of means among the Cuscuta stem collected from different host plant.

Table 7: Tocopherol contents of $n$ hexane extracts of Cuscuta stem collected from different host plants.

\begin{tabular}{|c|c|c|c|c|c|c|}
\hline$R_{2}$ values & Methanol & $80 \%$ methanol & Ethanol & $80 \%$ ethanol & water & n-hexane \\
\hline DPPH vs TPC & 0.916 & -0.545 & 0.521 & 0.517 & -0.012 & -0.131 \\
\hline DPPH vs TFC & 0.308 & 0.117 & 0.616 & 0.381 & -0.505 & -0.852 \\
\hline DPPH vs Reducing power & 0.561 & -0.451 & 0.203 & 0.213 & 0.180 & -0.1 \\
\hline DPPH vs \% inhibition of linoleic acid & 0.386 & 0.437 & 0.28 & 0.31 & -0.463 & 0.802 \\
\hline
\end{tabular}

Table 8: Correlation coefficient values.

\section{Correlation between antioxidant activity and total phenolics, flavonoids, and reducing power}

Total phenolic contents of absolute methanolic extract of Cuscuta stems showed a strong correlation with antiradical activity $\left(\mathrm{R}_{2}=0.916\right)$ followed by absolute ethanol $\left(\mathrm{R}_{2}=0.521\right)$ and $80 \%$ ethanol $\left(\mathrm{R}_{2}=0.517\right)$. This high correlation between DPPH scavenging activity and total phenolic contents suggests that major antioxidants might be phenolics in addition to tocopherols, flavonoids, ascorbic acid, sterols, carotenoids and synergism between antioxidants [26]. Other solvents extract of Cuscuta stems showed weak correlation $\left(\mathrm{R}_{2}=\right.$ -ve0.545--ve0.012) between TPC and DPPH scavenging activity. High correlation $\left(\mathrm{R}_{2}=0.912\right.$ at $\left.\mathrm{P}<0.05\right)$ between phenolic contents and antioxidant activity has also been reported earlier $[27,28]$. The correlation $\left(\mathrm{R}_{2}=0.616\right)$ between flavonoids and $\mathrm{DPPH}$ scavenging activity was found higher in ethanolic extracts of Cuscuta stems whereas other solvent extract showed weak correlation $\left(R_{2}=-0.852\right.$ 0.381) which is consistent with the findings of Imeh and Khokhar [29] and Ghimiri et al. [17] but contradictory to the findings of Kahkonen et al. [30] who reported the significant correlation between flavonoids and antioxidant activity of all solvent extracts. This weak relationship between antioxidant activity and total flavonoids contents may be caused by other factors like total phenolics with certain structure and hydroxyl position in the molecule can only act as proton donors and show free radical scavenging activity [31,32]. Moreover, significant differences in total phenolics, total flavonoids and DPPH scavenging activity can be attributable to extraction solvents, time of collecting samples, environment and genetic differences due to the different host plants [33]. The values of DPPH scavenging activity of methanolic extracts was correlated $\left(\mathrm{R}_{2}=0.561\right)$ with reducing power whereas other solvent extracts showed weak correlation $\left(\mathrm{R}_{2}=-0.1-0.213\right) \mathrm{DPPH}$ and reducing power. DPPH has very weak correlation $R_{2}=-0.463-0.437$ ) with the values of percent inhibition of linoleic acid peroxidation of all solvent extract except $n$-hexane extract $\left(\mathrm{R}_{2}=0.802\right)$ (Table 8).

\section{Conclusion}

The results of the present investigation revealed that aqueous solvent (80\% methanol, $80 \%$ ethanol) extracts of Cuscuta stems exhibited better antioxidant activities due to higher phenolic contents as well as reducing power. Antioxidant activity was found complimentary to the concentration of TPC and reducing power of the extract. The present data would certainly help to ascertain the potency of the Cuscuta stems as potential source of natural antioxidants to be used for nutraceutical and functional food applications. However, further research is needed to identify individual components forming antioxidative system and develop their applications for food and pharmaceutical industries.

\section{References}

1. Young IS, Woodside JV (2001) Antioxidants in health and disease. J Clin Pathol 54: 176-186.

2. Zaidi SF, Yamada K, Kadowaki M, Usmanghani K, Sugiyama T (2009) Bactericidal activity of medicinal plants, employed for the treatment of gastrointestinal ailments, against Helicobacter pylori. J Ethnopharmacol 121 286-291.

3. Pal DK, Mandal M, Senthilkumar GP, Padhiari A (2006) Antibacterial activity of Cuscuta reflexa stem and Corchorus olitorius seed. Fitoterapia 77: 589-591.

4. Mehjabeen, Ahmad M, Noor J, Ziaulhaq M, Mehboob SA, et al. (2011) Antimicrobial Screening of Some Plants of Medicinal Importance. Pak J Bot 43: 1773-1775.

5. Suresh V, Sruthi V, Padmaja B, Asha VV (2011) In vitro anti-inflammatory and anti-cancer activities of Cuscuta reflexa Roxb. J Ethnopharmacol 134: 872-877.

6. Costa-Lotufo LV, Khan MT, Ather A, Wilke DV, Jimenez PC, et al. (2005) Studies of the anticancer potential of plants used in Bangladeshi folk medicine. J Ethnopharmacol 99: 21-30.

7. Khan MT, Lampronti I, Martello D, Bianchi N, Jabbar S, et al. (2002) Identification of pyrogallol as an antiproliferative compound present in extracts from the medicinal plant Emblica officinalis: effects on in vitro cell growth of human tumor cell lines. Int J Oncol 21: 187-192.

8. Riaz M, Rasool N, Bukhari IH, Shahid M, Zubair M, et al. (2012) In vitro antimicrobial, antioxidant, cytotoxicity and GC-MS analysis of Mazus goodenifolius. Molecules 17: 14275-14287.

9. Anjum F, Shahid M, Bukhari SA, Anwar S, Latif S (2013) Study of Quality Characteristics and Efficacy of Extraction Solvent/ Technique on the Antioxidant Activity of Bitter Gourd Seed. J Food Process Technol 4: 205

10. Arshad MS, Anjum FM, Asghar A, Khan MI, Yasin M, et al. (2011) Lipid stability and antioxidant profile of microsomal fraction of broiler meat enriched with a-lipoic acid and a-tocopherol acetate. J Agric Food Chem 59: 7346-7352.

11. Mehmood N, Zubair M, Rizwan K, Rasool N, Shahid M, et al. (2012) Antioxidant Antimicrobial and Phytochemical Analysis of Cichorium intybus Seeds Extract and Various Organic Fractions. Iranian Journal of Pharmaceutical Research 11: $1145-1151$. 
Citation: Anjum F, Bukhari SA, Shahid M, Anwar S, Afzal M, et al. (2013) Comparative Evaluation of Antioxidant Potential of Parasitic Plant Collected from Different Hosts. J Food Process Technol 4: 228. doi:10.4172/2157-7110.1000228

12. Khan MM, Iqbal M, Hanif MA, Mahmood MS, Naqvi SA et al. (2012) Antioxidant and antipathogenic activities of citrus peel oils. Journal of Essential Oil Bearing Plants 15: 972-979

13. Steel RGD, Torrie JH, Dickey DA (1997) Principles and Procedures of Statistics: a biomaterial approach, (3rd Edn). McGraw Hill, New York, USA

14. Hsu B, Coupar IM, Ng K (2006) Antioxidant activity of hot water extract from the fruit of the Doum palm, Hyphaene thebaica. Food Chem 98: 317-328.

15. Siddhuraju P, Becker K (2003) Antioxidant properties of various solven extracts of total phenolic constituents from three different agroclimatic origins of drumstick tree (Moringa oleifera Lam.) leaves. J Agric Food Chem 51: 2144 2155.

16. Sultana B, Anwar F, Przybylski R (2007) Antioxidant activity of phenolic components present in barks of Azadirachta indica, Terminalia arjuna, Acacia nilotica, and Eugenia jambolana Lam. trees. Food Chem 104: 1106-1114.

17. Ghimire BK, Seong ES, Kim EH, Ghimeray AK, Yu CY, et al. (2011) A comparative evaluation of the antioxidant activity of some medicinal plants popularly used in Nepal. Journal of Medicinal Plants Research 5: 1884-1891.

18. Papuc C, Crivineanu M, Nicorescu V, Predescu C (2012) Reactive Oxygen Species Scavenging Activity and Hepatoprotective Effects of a Polyphenolic Extract Obtained from Cuscuta Europaea. REV CHIM (Bucharest) 9: 869-873.

19. Gupta VK, Sharma SK (2006) Plants as natural antioxidants. Natural product radiance 5: 326-334.

20. Sepehr MF, Jameie SB, Hajijafari B (2011) The Cuscuta kotschyana effects on breast cancer cells line MCF7. Journal of Medicinal Plants Research 5: 63446351.

21. Udavant PB, Satyanaryana SV, Upasani CD (2012) Preliminary screening of Cuscuta reflexa stems for Anti inflammatory and cytotoxic activity. Asian Pacific Journal of Tropical Biomedicine 2: S1303-S1307.

22. Liu H, Qiu N, Ding H, Yao R (2008) Polyphenols contents and antioxidan capacity of 68 Chinese herbals suitable for medicinal or food uses. Food Res Inter 41: 363-370.
23. Ashwani K Sapna R, Somiya SN (2012) Recent review on plant molecular biology, phytophysiology, phytochemistry and ethnopharmacology of Cuscuta reflexa. A wonderful parasitic plant. Int Research J Pharmacy 3: 30-38.

24. van der Kooij TA, Krupinska K, Krause K (2005) Tocochromanol content and composition in different species of the parasitic flowering plant genus Cuscuta. J Plant Physiol 162: 777-781

25. SzymaÅska R, Kruk J (2008) Tocopherol content and isomers' composition in selected plant species. Plant Physiol Biochem 46: 29-33.

26. Djeridane A, Yousfi M, Nadjemi B, Boutassouna D, Stocker P, et al. (2006) Antioxidant activity of some Algerian medicinal plants extracts containing phenolic compounds. Food Chem 97: 654-660.

27. Qusti SY, Abo-khatwa HN, Bin Lahwa MA (2010) Screening of antioxidan activity and phenolic content of selected food items cited in the holly quran. EJBS 2: 40-51.

28. Kratchanova M, Denev P, Ciz M, Lojek A, Mihailov A (2010) Evaluation of antioxidant activity of medicinal plants containing polyphenol compounds. Comparison of two extraction systems. Acta Biochim Pol 57: 229-234.

29. Imeh U, Khokhar S (2002) Distribution of conjugated and free phenols in fruits: antioxidant activity and cultivar variations. J Agric Food Chem 50: 6301-6306.

30. Kähkönen MP, Hopia Al, Vuorela HJ, Rauha JP, Pihlaja K, et al. (1999) Antioxidant activity of plant extracts containing phenolic compounds. J Agric Food Chem 47: 3954-3962.

31. Hou WC, Lin RD, Cheng KT, Hung YT, Cho CH, et al. (2003) Free radicalscavenging activity of Taiwanese native plants. Phytomedicine 10: 170-175.

32. Faizi S, Mughal NR, Khan RA, Khan SA, Ahmad A, et al. (2003) Evaluation of the antimicrobial property of Polyalthia longifolia var. pendula: isolation of a lactone as the active antibacterial agent from the ethanol extract of the stem. Phytother Res 17: 1177-1181.

33. Shan B, Cai YZ, Sun M, Corke H (2005) Antioxidant capacity of 26 spice extracts and characterization of their phenolic constituents. J Agric Food Chem 53: 7749-7759. 